\title{
Identifying the Relationship between Academic Self-motivation and the Mathematical Thinking: A Case Study of Secondary School Students
}

\author{
Salman Sahud Alotaibi \\ Department of Curriculum \& Teaching Methods, College of Education in Al-Kharj, Prince Sattam bin Abdulaziz University, \\ Al-Kharj, Saudi Arabia
}

Received July 15, 2020; Revised October 28, 2020; Accepted November 11, 2020

Cite This Paper in the following Citation Styles

(a): [1] Salman Sahud Alotaibi, "Identifying the Relationship between Academic Self-motivation and the Mathematical Thinking: A Case Study of Secondary School Students," Universal Journal of Educational Research, Vol. 8, No. 12A, pp. 7239 - 7245, 2020. DOI: 10.13189/ujer.2020.082506.

(b): Salman Sahud Alotaibi (2020). Identifying the Relationship between Academic Self-motivation and the Mathematical Thinking: A Case Study of Secondary School Students. Universal Journal of Educational Research, 8(12A), 7239 - 7245. DOI: 10.13189/ujer.2020.082506.

Copyright $\mathrm{C} 2020$ by authors, all rights reserved. Authors agree that this article remains permanently open access under the terms of the Creative Commons Attribution License 4.0 International License

\begin{abstract}
This research paper aims to examine and evaluate co-relationship between the academic self-motivation and the mathematical thinking among secondary school students in Al-Sulail and Wadi Al-Dawassir Governorates, Saudi Arabia. The purpose of the study is to find out the role of self-efficacy in learning mathematical concepts and skills. It is assumed that math self-concept affects math performance both directly and indirectly. For the assessment of this assumption, data were collected by using a questionnaire for academic self-motivation, and a test for measuring the mathematical thinking of the subjects. The tools were applied to secondary school students and distributed electronically to a number of 254 students. Out of the total participants, 238 students responded to the questionnaire. The data were analyzed using the SSPS software. Based on the overall results and the discussion of this research, it was concluded that academic self-motivation and mathematical thinking have either less dependence or no dependence at all. This outcome is based on the analysis of the study sample.
\end{abstract}

Keywords Student Motivation, Mathematical Thinking, Teaching Mathematics, Effective Evaluation

\section{Introduction}

The transfer of responsibility from learning-centered approach to the learner-centered approach and away from the instructors is an increasingly important area in pedagogy, in which, the students develop the self-skills necessary to be a life-long learner and a self-sufficient, productive citizen. There is a consensus among psychologists, and educationalists that when individuals are able to self-motivate and follow the behavioral processes, they can boost their ability to achieve the desired goals.

Mathematical knowledge is supposed to have insightful and abstract knowledge. That is when learners advance on academic levels and further move on tertiary education, and in order to achieve successes and gain mathematical concepts and skills, they need to recall the mathematical concept that they have learned previously.

In fact, the Ministry of Education in Saudi Arabia has approved advanced mathematics courses that were adapted and Arabized by following the global mathematics chains (McGraw-Hill). The content prescribed by this model has been applied for more than ten years ago. The aims of this implementation were to raise the level of educational competencies for the Kingdom's students in mathematics and science subjects and to keep pace with the rapid development and progress, so that they can compete with their peers at the global level.

With this aim in mind, this research aims to establish the connection between academic self-motivation and mathematical thinking among the students of secondary 
school at Al-Sulail and Wadi Al-Dawassir Governorates, Saudi Arabia. In the light of this objective, the research seeks to address various questions. Some of the major questions are as follows:

- What is the level of mathematical thinking among secondary school students at Al-Sulail and Wadi Al-Dawassir Governorates?

- The extent of academic self-motivation among the students of secondary school at Al-Sulail and Wadi Al-Dawassir Governorates.

- What is the possible connection between academic self-motivation and mathematical thinking skills among the secondary school students at Al-Sulail and Wadi Al-Dawassir Governorates?

It's relevant to say here that, the data collected for the current study are assumed to be more updated than the one applied in the previous studies. Further, the sampling used for the present analysis was collected during the second semester students of the year 2020.

The rest other parts of this research paper have been developed in the following ways: section 2 of this paper incorporates theoretical frameworks; section 3 describes methodology and emphasizes on survey instrument development, data collection procedures, and characteristics of participants; following section 4 focuses on key results and discussion of them, and finally there is an exhaustive conclusion in section 5 .

\section{Problem of Research}

A number of scholars have variously researched and published to investigate and identify the relationship between the academic self-motivation and the mathematical thinking, however, there is no study known to the researcher which has critically examined on this particular aspect. This paper therefore, seeks to examine how academic self-motivation and mathematical thinking are related to each other particular in the context of secondary school students in Riyadh. To begin with, the study attempts to provide a solid foundation to comprehend deeper of the concept of academic self-motivation and mathematical thinking skills among secondary school students in KSA context. An extensive piece of literature was published on academic self-motivation in developed countries, however, only a few similar studies have been done in the Middle East, specifically in KSA.

Moreover, the researcher postulated that one finds statistically substantial correlation among the academic self-motivation, mathematical thinking, level of academic self-motivation and level of mathematical thinking.

This research is expected to contribute significantly to examine co-relationship between the academic self-motivation and the mathematical thinking so that it can be used for academic performance. To that end, the present study is divided into sections each of which covers important aspects of the topic under investigation.

\section{Related Literature and Theoretical Background}

\subsection{Academic Self-motivation}

There is a vast amount of research studies outlining the motivation of the students. According to Bong \& Clark (1999), Dekker \& Fischer (2008), development of an understanding of academic motivation has, in fact, been of distinct importance in the field of education, as students' motivation has been identified as a significant element in student success and development at school [1,2].

Many researchers such as Ferrer-Caja \& Weiss (2000), Standage, Duda, \& Ntoumanis, (2006) found that motivation is highly required for academic achievement and performance $[3,4]$. In this regard, one of the most significant researches done by Gagne \& Deci (2005), found that self-determination theory is considered to be one of the most important and useful theories for measuring the motivation level students [5]. This finding has attracted extensive interest in a number of research discourses.

In a study carried out by Manzo (2008), in which she assessed the effect that the absence of motivation can hamper the academic progress of the students. She further highlighted that students should be motivated and supported time to time as most of them don't get selfmotivation and support at home [6].

Wigfield et. al. (2004) conducted an in-depth study on student motivation. He categorizes the concept of 'motivation' into three parts. They are intrinsic and extrinsic, competence and self-efficacy, and social motivation [7]. Ryan \& Deci (2000) defines intrinsic motivation as discovering challenges and problems so that to teach and learn simultaneously. He also defines extrinsic motivation as external driving forces such as rewards and praise, which inspire to achieve [8].

In social cognitive theory, the concept of self-efficacy is an assessment of your ability to take actions to successfully achieve the desired aims [9]. In a similar study, the statistical connection of academic self-efficacy to the academic performance of high school students was found by Al-Zahrani (2016) [10]. The findings of Jubara \& Al-Shahrouri's study (2016) also revealed the importance of exploring the relationship between mathematical and creative thinking, and the results showed the correlation between them [11]. The result enhanced the value of mathematical thinking and its association with several areas that may affect the learning of a high school student who has several characteristics for growth, making it an area of interest for teachers and experts. Further, it requires additional initiatives and activities to support the learning process.

Utilizing the above methods, students can be motivated or inspired by any factor. In other words, motivation is not only limited to one factor or idea, and different combinations can affect different students. One major 
implication of the motivation is that the overloaded mathematical content will not be a hurdle if the students take it as enjoyable activity and is meant for their achievement and growth. In this way, this situation will work as the formation of effective excitement and a tendency to learn.

\subsection{Mathematical Thinking}

Developing mathematical thinking is one of considerable objective of mathematics education and it is widely accepted as a key factor in learning goal and objective in mathematical education. Several studies investigating mathematical thinking have been carried out, Skempt (1976), for instance, emphasized that mathematical thinking should not be used as an independent tool. Instead it should be studied and applied in relation to other relevant factors [12].

In Drijvers P. et al. (2019) illustrated the role of mathematical thinking and identified some major elements, which he believed were important elements in mathematical thinking, problem solving, modeling and abstraction [13].

Despite considering mathematical thinking important for learning, views on what mathematical thinking really is, seem less common. In this respect, Burton (1984) defined mathematical thinking as an approach to enhance knowledge and understanding of mathematical analysis. He believed that mathematical thinking has basically three features: mathematical thinking operations, processes and dynamics [14].

Mason, Burton \& Stacey (2010) showed that the mathematical thinking is a mechanism and an incredibly complex operation. It requires proper illustrations and examples for concise understanding. Furthermore, mathematical analysis can be interpreted by collecting different researches on mathematical objects as a means of understanding mathematical problems. Together these studies provide important insights into the present discussion [15].

Having analyzed the content of the six prescribed math books that the students interacted with during the three school years within the framework of the secondary stage, they have acquired various mathematical skills and values in algebra, statistics, engineering, mathematical analysis, number theory, and mathematical functions, which have yet to be given more attention, capabilities, and competencies.

\subsection{Relationship between Academic self-motivation and Mathematical Thinking}

In past, many researchers have researched on the relationship between academic self-motivation and mathematical thinking. Michaelides et. al. (2019) state that the most important thing is that most of the motivation theories seek achievement assessment [16].
A significant number of studies (Osborne et al. 2003; Hattie, 2009; Karadag 2017; Lee and Stankov 2018) have examined factors of student motivation and their relationship with efficiency and mathematical thinking. The motivations and interest of students affect their learning and success on the examination of school subjects, including mathematics. They found a positive relationship between student motivation and academic achievement on the basis of their investigations and evaluations. Most research findings indicate that more or less motivational levels have a positive link with mathematical learning and performance [17- 20].

Further, Deci and Ryan (2002) also argue that the need for competence leads students to perform mathematical tasks properly and to try to retain and improve their mathematical understanding [21].

\section{Methodology}

This section describes in details about the way research was accompanied. It also provides information about how the survey instrument was developed, and how the sample was selected and the data were collected in some details.

\subsection{Survey Instrument Development}

Following recent research practice, measurement instruments for all survey items were developed based on previous extensive literature reviews. Moreover, interviews with three experts in this research field assisted the generation of constructs and measures. The main objective was to evaluate whether the measurement system adapted has fit and appropriate survey structure or not.

Previously also many researchers including Griffith \& Dimitrova (2014) emphasized that proposed conceptual model should be evaluated by experts of the field in order to evaluate its validity, improve suggested change in questionnaire, and generate knowledge on how the survey should be implemented [22]. Some scale items were dropped and others were rephrased based on the feedback obtained from them. Additionally, two pilot tests were carried out to check the validity and reliability of the measurement items. It is worth noticing that there was no growing concern about the scope, complexity or consistency of the questionnaire in the pilot study.

Various statistical approaches were employed to assess if each construct was representative of the survey instrument. The questionnaire comprises two sections: The first section was intended to gather descriptive data about the respondents whereas, the second section was specifically designed to collect data related to the mathematical thinking test.

\subsection{Data Collection Procedures}

With regard to data collection and data analysis, the questionnaires were filled by all participants. Approval was 
taken and informed consent from all the respective school authorities at Al-Sulail and Wadi Al-Dawassir Governorates. All the participants were also informed in advance and their consent was taken.

The researchers gave detailed instructions on how to complete the questionnaire before the questionnaire was given to students and also provided some practices. All participants were taken into assurance that their information the collected data will be kept confidential and will be used solely for research purposes. The completion of questionnaire, conducting test for measuring mathematical thinking and academic self-motivation took altogether about 45 minutes to complete the task. Immediately, all the questionnaires were collected directly after they were completed by all the participants.

The second section was subdivided into two elements: The first component deals with mathematical thinking test, comprising multiple-choice types, formulated after reviewing the content of mathematics books. The questionnaire's questions were thoroughly designed, that is, the researcher was very keen to make them as direct as possible and to avoid any ambiguity, in order to fit with the level of the mathematical concept and the characteristics of learners. This section comprises 12 multiple choice questions related to the prescribed books. Given below is the list of questions in component one:

\begin{tabular}{|c|c|}
\hline SN & Component one: mathematical thinking test \\
\hline 1 & $\begin{array}{l}\text { If you throw a cube numbered } 1 \text { to } 6 \text { at once, the probability } \\
\text { of appearing less than } 4 \text { is: }\end{array}$ \\
\hline 2 & $\begin{array}{l}\text { The value of } \mathrm{x} \text { which makes the function } \mathrm{f}(\mathrm{x})=3 /(2 \mathrm{x}+5) \\
\text { is: }\end{array}$ \\
\hline 3 & $\begin{array}{c}\text { The thirteenth term in an arithmetic sequence: } 9,16 \text {, } \\
23,30 \ldots \ldots \ldots \text { is }\end{array}$ \\
\hline 4 & $\begin{array}{l}\text { The ratio of the length of a rectangle to its width is } 5: 12 \text {. If } \\
\text { the area of the rectangle is } 240 \text { square centimeters, how long } \\
\text { is the diameter of the rectangle? }\end{array}$ \\
\hline 5 & $\begin{array}{l}\text { The equation of a line that passes through the two points }(1 \text {, } \\
\qquad 4),(1,3) \text { is }\end{array}$ \\
\hline 6 & $\begin{array}{l}\text { If the length of the two sides in a triangle are } 3 \mathrm{~cm}, 7 \mathrm{~cm} \text { then } \\
\text { the smallest natural number that can represent the length of } \\
\text { the third side is }\end{array}$ \\
\hline 7 & $\begin{array}{l}\text { If } y \text { is proportional to } x \text {, and } y=24 \text { at } x=8 \text {, then the value of } \\
\qquad x \text { at } y=48 \text { is: }\end{array}$ \\
\hline 8 & The value of the interior angle of a regular nanometer is: \\
\hline 9 & $\begin{array}{c}\text { Ahmed wanted to buy a dress, so he had the space to buy a } \\
\text { dress in three colors, or } 4 \text { shapes, or two different lengths. } \\
\text { The total number of options Ahmad had: }\end{array}$ \\
\hline 10 & $\begin{array}{l}\text { The curve of the function } \mathrm{f}(\mathrm{x})=2 \mathrm{x}+2 \mathrm{y} \text { interrupts at the } \\
\text { point: }\end{array}$ \\
\hline 11 & $\begin{array}{c}\text { What shape could be an example of counter-guessing: "If the } \\
\text { diagonals of a quadrangle are congruent then it is a } \\
\text { rectangle"? }\end{array}$ \\
\hline 12 & $\begin{array}{c}\text { The image of point } \mathrm{A}(4,1) \text { resulting from a reflection } \\
\text { around the line } \mathrm{y}=\mathrm{x} \text { is: }\end{array}$ \\
\hline
\end{tabular}

The second component is meant for the academic self-motivation test. This section comprises 24 questions related to academic self-motivation test with three response options: 'Always - sometimes - rarely.' The following is the list of questionnaires related to academic self-motivation test:

\begin{tabular}{|c|c|}
\hline SN & Component two: academic self-motivation test \\
\hline 1 & I give up quickly when my mistakes abound. \\
\hline 2 & $\begin{array}{l}\text { Insist on performing the assigned study tasks, however } \\
\text { difficult they are. }\end{array}$ \\
\hline 3 & $\begin{array}{l}\text { I use more than one method to solve the study problems I } \\
\text { face. }\end{array}$ \\
\hline 4 & I reach my goals no matter how hard I face. \\
\hline 5 & I feel frustrated when I fail to do the study assignment. \\
\hline 6 & Leave school work before its completion if it is difficult. \\
\hline 7 & $\begin{array}{c}\text { I enjoy learning especially when it includes new } \\
\text { experiences. }\end{array}$ \\
\hline 8 & $\begin{array}{c}\text { I find inner joy when I participate in solving my classmates' } \\
\text { problems. }\end{array}$ \\
\hline 9 & $\begin{array}{l}\text { I volunteer to complete educational assignments in the } \\
\text { classroom. }\end{array}$ \\
\hline 10 & I am happy when I complete my study assignments. \\
\hline 11 & I get bored when I read non-school books. \\
\hline 12 & I am happy when I do my homework. \\
\hline 13 & $\begin{array}{l}\text { I find it difficult to concentrate while the teacher is } \\
\text { explaining the lesson. }\end{array}$ \\
\hline 14 & Daydreaming distracts me from my homework. \\
\hline 15 & $\begin{array}{l}\text { I repeat my study assignments more than once until I perfect } \\
\text { it. }\end{array}$ \\
\hline 16 & I rely on myself to solve difficult issues. \\
\hline 17 & I do my homework with care and attention. \\
\hline 18 & I give more time to difficult school subjects to master them. \\
\hline 19 & Learn new things from my interests. \\
\hline 20 & Ask questions that the teacher describes as great. \\
\hline 21 & When I do wrong, I like to get the right answer myself. \\
\hline 22 & $\begin{array}{l}\text { I try to think about difficult issues so that I understand them } \\
\text { myself. }\end{array}$ \\
\hline 23 & $\begin{array}{l}\text { I do school assignments to come up with a lot of things I } \\
\text { want to know. }\end{array}$ \\
\hline 24 & $\begin{array}{l}\text { I set myself renewed goals and I am not convinced of my } \\
\text { goals. }\end{array}$ \\
\hline
\end{tabular}

\subsection{Participants}

The data collection task was administered by 254 students from secondary schools at Al-Sulail and Wadi Al-Dawassir Governorates, Saudi Arabia. These students accomplished the task voluntarily. 238 responses were valid. The participants included $40 \%$ students from Al-Sulail Governorates secondary schools and 60\% students from Wadi Al-Dawassir Governorates schools. 167 (70.6\%) female students and 71 (29.4\%) male students participated in the sampling task. There were more female students $167(70.6 \%)$ than male students $71(29.4 \%)$ in the sample. The students in the sample were 15 to 18 years of age. The average mean age of the participants is 16.5 years. The two Governorates schools that have chosen for study purpose, they have almost similar resources, levels of academic achievement and opportunity, and even school environment and cultural background. 


\section{Analysis}

\subsection{Measure Validity and Reliability}

As per the guidelines of Anderson and Gerbing (1988), validity and reliability assessments have been anticipated. The researcher initially conducted a number of analyses of factors to be used for this research [23]. The final analysis indicates that theoretical expectations of selected factors are reliable and consistent. Cronbach's $\alpha$ coefficients scores for the main study were constructed to test the inter-item constancy reliability.

According to Hair et al (2006) and Nunally \& Berstein (1994) Cronbach's $\alpha$ coefficients should be above the threshold of 0.70. Cheng-Wen Lee (2007) has opinion that if the researcher fails to achieve the desired statistical output, the researcher can eliminate and add some indicators to make the result better and productive [26]. Here, the latent and observed variables of Cronbach's coefficient $\alpha$ values exceeded 0.80 and even exceeded 0.87 of the certain constructs. Moreover, the composite reliability (CR) test was checked and average variance (AVE) was extracted for each construct was equal or above 0.50 and 0.6 respectively [27]. Thus, the measurements were sufficiently reliable and have satisfactory convergent validity.

\section{Result and Discussion}

Table 1. Mathematical thinking test and male and female students' performance

\begin{tabular}{|c|c|c|c|}
\hline $\begin{array}{c}\text { Mathematical } \\
\text { thinking test }\end{array}$ & $\mathrm{N}$ & Mean & Std. Deviation \\
\cline { 2 - 4 } & 238 & 3.9118 & 2.05530 \\
\hline
\end{tabular}

As shown in the above table-1, a total of 238 students including both male and female responded to the questionnaire and the data received from them were analyzed to test their mathematical thinking. The arithmetic average is found 3.9119 out of (12) with a standard deviation of 2.0554 .

The outcome was not very encouraging, although the level of the test items was within the direct level, which most students are supposed to master after analyzing the content of the high school mathematics book. Only direct questions were derived that reflect a quick understanding of the course requirements.

The results above are similar to the results of Al Shihri's study (2016) on the secondary school students in the Kingdom of Saudi Arabia [28]. The mathematical reasoning that was used for mathematical inferential thinking was found low. Therefore, the result emphasizes on the need of more confined studies, which will help to understand the situation to realize fresh attitude towards learning development.

As shown in the table 2. that the average performance of second-grade students in mathematical thinking test was (4.0177) out of 12, and the average performance of third-grade students in the same test was (3.8160) out of 12 . This result indicates minor progress in the test performance for the benefit of students. However, in the second secondary class, the higher grade is supposed to be better in performance based on the experience and skills acquired.

Based on the results obtained from the Independent Samples Test of the differences between the performance of the mathematical reasoning test according to the grade (second secondary and third secondary), it has also been further suggested that the average performance of the second secondary and third grade secondary students is statistically very marginal, where $\mathrm{T}=0.755$, and the value of sig. $=0.451$. This confirms the convergence between the two averages, and the differences are insignificant.

The table 3 compares the average performance of the male students in the mathematical thinking with their female counterparts, the male students' test was (4.7465) out of 12, whereas the average performance of the female students in the same test was (3.5569) out of 12, which indicates better performance of the female students rather than the male students.

It was observed from the Independent Samples Test of the differences between the performance of the mathematical thinking test according to gender (male, female), that statistically, the researcher found no difference in average performance of male and female high school students, where $\mathrm{T}=4.228$, and the value of sig. $=$ 0.000 , and therefore the difference of Mean values is higher $(\mathrm{M} 1=4.7465>\mathrm{M} 2=3.5569)$, which confirms that their performance was good in the various items of the test.

Table 2. Results of the Independent Samples Test for the difference between students' performance in mathematical thinking skills testing according to stage (second and third secondary)

\begin{tabular}{|c|c|c|c|c|c|c|}
\hline Class & Mean & $\mathrm{N}$ & Std. Deviation & $\mathrm{t}$ & Df & Sig. (2-tailed) \\
\cline { 1 - 4 } The second secondary & 4.0177 & 113 & 2.26378 & \multirow{2}{*}{0.755} & \multirow{2}{*}{236} & 0.451 \\
\hline Third secondary & 3.8160 & 125 & 1.85082 & & \\
\hline
\end{tabular}

Table 3. Independent Samples Test for The Difference Between Student Performance And Mathematical Thinking Skills By Type (Male, Female)

\begin{tabular}{|c|c|c|c|c|c|c|c|}
\hline \multirow{2}{*}{$\begin{array}{c}\text { Mathematical } \\
\text { thinking test }\end{array}$} & Class & $\mathrm{N}$ & Mean & Std. Deviation & $\mathrm{T}$ & df & Sig. (2-tailed) \\
\cline { 2 - 7 } & male & 71 & 4.7465 & 2.16939 & \multirow{2}{*}{4.228} & \multirow{2}{*}{0.000} \\
\cline { 2 - 7 } & female & 167 & 3.5569 & 1.90309 & & \\
\hline
\end{tabular}


Table 4. The degree of correlation between male and female students 'performance in the mathematical thinking test and the academic self-motivation scale

\begin{tabular}{|c|c|c|c|c|c|}
\hline & Mean & Std. Deviation & $\mathrm{N}$ & $\begin{array}{c}\text { Pearson } \\
\text { Correlation }\end{array}$ & Sig. (2-tailed) \\
\cline { 1 - 3 } Mathematical thinking test & 3.9118 & 2.05530 & \multirow{2}{*}{238} & $-0.098-$ & 0.132 \\
\cline { 1 - 5 } Academic motivation scale & 2.3053 & 0.23160 & & \\
\hline
\end{tabular}

\section{Correlations}

It is clear from the above table 4 . that there is no correlation between the level of performance of high school students in the mathematical thinking test and the measure of self-academic motivation, as the value of (Pearson Correlation $=-0.098-$ ), and the value of sig. $=$ 0.132 , which confirm that the study sample reveals hardly any association between the independent variables.

The majority of the literature reviews included in these studies show that students who are more self-sufficient and motivated in mathematics and students who value the subject achieve better results. However, a few researchers have shown that the close link between academic motivation and mathematical thinking is not necessarily significant. In this context, Hidi and Harackiewicz (2000) suggest that the academic motivation of adolescents is declining over time. Recent studies show that as younger children grow older, their preferences and attitudes towards schools in general and specific subjects such as mathematics, art and science are starting to worsen[29]. Further, Musso et al. (2012) found that the impact of student motivation on their learning and momentum parameters was not quite significant. Such research outcome is not limited to these but many more in this line [30].

The present research is also the continuation of the above mentioned research outcome. Though self-motivation is important in boosting performance however teaching environment differs from one place to another. So the connection between academic self-motivation and mathematical thinking is not always feasible.

\section{Conclusions and Implications}

This research study is an attempt to investigate and identify the connection of academic self-motivation and the mathematical thinking among Secondary school students in order to bridge the gap between them for better performance.

In this research, it is assumed that the academic self-motivation and the mathematical thinking are correlated and affect academic achievement. The proposed theoretical framework for analyzing the students' academic self-motivation is considered to be one of the important factors to figure out the students' goals. Nevertheless, the effect of the students' academic self-motivation on their mathematical thinking is not significant. To conclude, this study does not show similar results to the studies of various researchers reviewed in the literature review section.

As a matter of fact, the teaching of Mathematics is a "difficult subject for most of the students in the world. The success of the students largely depends on the continuous and rigorous practice under the tutelage of an expert teacher" [31]. To make it enjoyable and gear towards making students understand, there are some requirements which can introduce students to real world. Additionally, some effective approaches can be implemented to develop competency among the student in mathematics learning. The curriculum designers, teachers, and curriculum planners may need to adopt flexible teaching ideas and strategies that stimulate the role of learners in secondary level to aid them advance to the next level.

Moreover, there is a real challenge in facing the amount of mathematical information and its achievement in light of the reliance of education in KSA on written tests to measure the achievement of mathematical content during learning. Furthermore, after finishing the learning as a final evaluation test, the students are supposed to apprehend the skills and strategies in light of the intensity of the subjects and other courses that the student interacts with them.

\section{Further Research Suggestions}

Critical thinking skills are the essential requirements in mathematics teaching. There are various factors, which are responsible to develop thinking skills. However, academic self-motivation is one of the foremost factors responsible for enhancing thinking skills. Self-motivation depends upon psychological and socio-economic factors. Further research can be done investigating the other motivation factors. Research can also work on the different aspects responsible for developing critical skills.

\section{Acknowledgement}

I wish to extend my special thanks to the Deanship of Scientific Research at Prince Sattam Bin Abdulaziz University for funding this project under the research project 2018/02/8332.

\section{REFERENCES}

[1] Bong, M., \& Clark, R. E. (1999). Comparison between self-concept and self-efficacy in academic motivation research. Educational Psychologist, 34(3), 139-153. 
[2] Dekker, S., \& Fischer, R. (2008). Cultural differences in academic motivation goals: A meta-analysis across 13 societies. The Journal of Educational Research, 102(2), 99-110.

[3] Ferrer-Caja, E., \& Weiss, M. R. (2000). Predictors of intrinsic motivation among adolescent students in physical education. Research Quarterly for Exercise and Sport, 71(3), 267-279.

[4] Standage, M., Duda, J. L., \& Ntoumanis, N. (2006). Students' motivational processes and their relationship to teacher ratings in school physical education: A self-determination theory approach. Research Quarterly for Exercise and Sport, 77(1), 100-110.

[5] Gagne, M., \& Deci, E. L. (2005). Self-determination theory and work motivation. Journal of Organizational Behavior, 26(4), 331-362.

[6] Manzo, K. (2008). Motivating students in the middle years. Education Week, 27(28), 21-24.

[7] Wigfield, A., Guthrie, J. T., Tonks, S., \& Perencevich, K. C. (2004). Children's motivation for reading: domain specificity and instructional influences. Journal of Educational Research, 97, 299-309.

[8] Ryan, R. M., \& Deci, E. L. (2000). Intrinsic and extrinsic motivations: classic definitions and new directions. Contemporary Educational Psychology, 25, 54-67.

[9] Bandura, A. (1997). Self-efficacy: The Exercise of Control. New York, NY: Freeman

[10] Al-Zahrani, M. R. (2016). Academic self-efficacy and its relationship to mental habits and academic achievement for secondary school students in Makkah Al-Mukarramah. The World of Education: The Arab Foundation for Scientific Consultation and Human Resources Development Q17, N 54, 13-90.

[11] Jubarah, K., \& Al-Shahrouri, M. (2016). The relationship between the level of mathematical thinking and creative thinking skills among high school students in the city of Hail, Saudi Arabia. Journal of the Faculty of Education for Educational Sciences: Ain Shams University, 40, No.1, $237-278$.

[12] Skemp, R. R. (1976). Relational understanding and instrumental understanding. Mathematics Teaching, 77, 20-26.

[13] Drijvers, P., Kodde, H., \& Doorman, M. (2019). Assessing mathematical thinking as part of curriculum reform in the Netherland. Educational Studies in Mathematics.

[14] Burton, L. (1984). Mathematical thinking: The struggle for meaning. Journal for Research in Mathematics Education, $15,1,35-49$.

[15] Mason, J., Burton, L., \& Stacey, K. (2010). Thinking Mathematically. Inggris: Pearson Education Limited.

[16] Michaelides, M.P, Brown, G. T. L., Eklöf, H., \& Papanastasiou, E. C., (2019). "The relationship of motivation with achievement in Mathematics". Motivational Profiles in TIMSS Mathematics. pp 9-23 Switzerland: Springer International Publishing. Retrieved from https://link.springer.com/chapter/10.1007/978-3-03026183-2 2.
[17] Osborne, J., Simon, S., \& Collins, S. (2003). Attitudes towards science: A review of the literature and its implications. International Journal of Science Education, 25(9), 1049-1079.

[18] Hattie, J. A. C. (2009). Visible learning: A synthesis of over 800 meta-analyses relating to achievement. London, UK: Routledge.

[19] Karadag, E. (Ed.). (2017). The factors effecting student achievement: Meta-analysis of empirical studies. Cham, Switzerland: Springer International Publishing. Retrieved from https://www.springer.com/gp/book/9783319560823.

[20] Lee, J., \& Stankov, L. (2018). Non-cognitive predictors of academic achievement: Evidence from TIMSS and PISA. Learning and Individual Differences, 65, 50-64.

[21] Deci, E. L., \& Ryan, R. M. (2000). The "what" and "why" of goal pursuits: Human needs and the self-determination of behavior. Psychological Inquiry, 11(4), 227-268.

[22] Griffith, D. A., \& Dimitrova, B. V. "Business and Cultural Aspects of Psychic Distance and Complementarity of Capabilities in Export Relationships". Journal of International Marketing, Volume: 22 issue: 3, page(s): 50-67, September 1, 2014. https://doi.org/10.1509/jim.14.0 019

[23] Anderson, J. C., and Gerbing, D. W. (1988). Structural Equation Modeling in Practice: A Review and Recommended Two-Step Approach. Psychological Bulletin, 103(3), 411-423.

[24] Hair, J. F., Black, W. C., Babin, B. J., Anderson, R. E. and Tatham, R. L. (2006). Multivariate Data Analysis. 6th edition. Upper Saddle River, New Jersey: Prentice Hall.

[25] Nunally, J., \& Berstein, I. Psychometric Theory, 3rd edn. McGraw-Hill, New York, 1994.

[26] Cheng-Wen Lee, 2007. "The innovation and success of consumer electronics using new product development process," International Journal of Innovation and Learning, Inderscience Enterprises Ltd, vol. 4(6), pages 587-611.

[27] Netemeyer, R. G., Johnston, M. W., \& Burton, S. (1990), Analysis of role conflict and role ambiguity in a structural equations framework. Journal of Applied Psychology, 75(2), 148-157. https://doi.org/10.1037/0021-9010.75.2.148

[28] AL Shihri, Z. (2016). A level enabling secondary school students to think mathematical reasoning. King Khalid University, Journal for Educational Sciences, p. 27 (2016): 173-186.

[29] Hidi, S., \& Harackiewicz, J. H. (2000). "Motivating the academically unmotivated: a critical issue for the $21 \mathrm{st}$ century," Review of Educational Research, vol. 70, no. 2, pp. 151-179.

[30] Musso, M., Kyndt, E., Cascallar, E., \& F. Dochy, F. (2012). "Predicting mathematical performance: the effect of cognitive processes and self-regulation factors," Education Research International, vol. 2012, Volume 2012 |Article ID 250719 | https://doi.org/10.1155/2012/250719.

[31] Alotaibi, S. S., \& Kumar, T. (2019). Promoting teaching and learning performance in mathematics classroom through e-learning. Opción, Año 35, Especial No.19 (2019):2363-2378. 